\title{
ENHANCING SAFETY OF HYDROGEN CONTAINMENT COMPONENTS THROUGH MATERIALS TESTING UNDER IN- SERVICE CONDITIONS
}

\author{
Somerday, B.P., Campbell, J.A., Lee, K.L., Ronevich, J.A.*, and San Marchi, C. \\ Sandia National Laboratories, 7011 East Ave., Livermore CA, 94550, USA \\ jaronev@sandia.gov
}

\begin{abstract}
The capabilities in the Hydrogen Effects on Materials Laboratory (HEML) at Sandia National Laboratories and the related materials testing activities that support standards development and technology deployment are reviewed. The specialized systems in the HEML allow testing of structural materials under in-service conditions, such as hydrogen gas pressures up to $138 \mathrm{MPa}$, temperatures from ambient to $203 \mathrm{~K}$, and cyclic mechanical loading. Examples of materials testing under hydrogen gas exposure featured in the HEML include stainless steels for fuel cell vehicle balance of plant components and Cr-Mo steels for stationary seamless pressure vessels.
\end{abstract}

\subsection{INTRODUCTION}

It is well known that hydrogen gas exposure degrades the mechanical properties of structural materials, a phenomenon typically referred to as hydrogen embrittlement. The process of hydrogen embrittlement in hydrogen gas environments involves several steps, including: 1) dissociative chemisorption of molecular hydrogen on the material surface, 2) sub-surface absorption of atomic hydrogen into the bulk material lattice, 3) diffusion of atomic hydrogen driven by stress and hydrogenconcentration gradients, 4) trapping of atomic hydrogen at sites (defects) with more free volume than the material lattice, and 5) atomic hydrogen-defect interactions that act in concert with applied stress to activate the embrittlement mechanism. This sequence leading to hydrogen embrittlement is particularly relevant to ambient-temperature conditions. Although the specific embrittlement mechanism can depend on material characteristics and environmental conditions, typical manifestations of hydrogen embrittlement are reduced tensile ductility, time-dependent subcritical crack extension, and accelerated fatigue crack initiation and growth.

Since hydrogen embrittlement can activate or accelerate crack extension, it must be considered in safety analyses of hydrogen containment components. Evolving design and safety qualification standards for hydrogen containment components account for hydrogen embrittlement through material testing. Quantification of hydrogen embrittlement for the purpose of reliably informing design and safety qualification standards must ensure that material testing reflects in-service conditions. For example, materials must represent commercial products and test conditions such as hydrogen gas pressure and temperature must represent the service environment. Since in-service environmental conditions are expected to include hydrogen gas pressures as high as $100 \mathrm{MPa}$ and temperatures as low as $223 \mathrm{~K}$, material testing under these conditions requires challenging procedures and sophisticated equipment. There are a limited number of laboratories in the international research and engineering communities that are capable of performing material testing under in-service conditions relevant to hydrogen containment components; the Hydrogen Effects on Materials Laboratory at Sandia National Laboratories (Livermore, CA) is one of them.

This review describes systems in the Hydrogen Effects on Materials Laboratory (HEML) for performing material tests under hydrogen gas pressures, temperatures, and mechanical stress ranges that are relevant to hydrogen containment components. Although the operating envelope for the laboratory includes hydrogen gas pressures up to $138 \mathrm{MPa}$, temperatures from ambient to $203 \mathrm{~K}$, and mechanical stress from static to cyclic, each test system in the laboratory can only cover part of the envelope. For example, the system dedicated to cyclic stressing of materials can operate with 
hydrogen gas pressures up to $138 \mathrm{MPa}$ but is limited to room temperature. In addition to describing physical assets in the HEML, this review summarizes materials testing activities in the laboratory that support the development and exercising of design and safety qualification standards for hydrogen containment components. Examples of materials testing activities are selected to highlight the functionality of different systems in the laboratory.

\subsection{TEST SYSTEMS IN HYDROGEN EFFECTS ON MATERIALS LABORATORY}

The Hydrogen Effects on Materials Laboratory features three distinct test systems. Collectively, the systems enable measurement of mechanical properties such as tensile ductility, time-dependent subcritical crack extension, and accelerated fatigue crack initiation and growth over a range of hydrogen exposure and mechanical stress conditions. The common specification for the systems is to expose materials to hydrogen gas at high pressure, in which the maximum pressure for each system is at least $138 \mathrm{MPa}$. This high-pressure capacity is the central characteristic that distinguishes the HEML from similar facilities in the international research and engineering communities. Details of the three test systems in the HEML are summarized below.

\subsection{Dynamic-Load Testing in High-Pressure Hydrogen Gas}

With this system, material test specimens are exposed to high-pressure hydrogen gas while subjected to different mechanical-loading formats, e.g., monotonically increasing or cyclic. These loading formats allow measurement of mechanical properties such as tensile strength and ductility, fatigue strength, fatigue crack growth rates, and time-dependent subcritical cracking thresholds. The two central components in this system are a conventional mechanical test frame and a custom-designed pressure vessel integrated into the test-frame load train (Fig. 1). The pressure vessel is rated for 138 $\mathrm{MPa}$ pressure and exhibits several key attributes to ensure the system can operate according to its intended function.

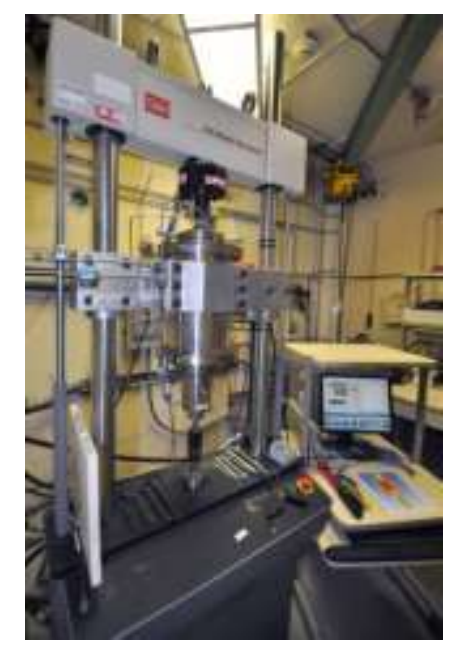

Figure 1. Dynamic-load testing in high-pressure hydrogen gas system

The key features of the pressure vessel are its materials of construction, pressure balance chamber, gas seals, and internal instrumentation. The pressure-boundary components (shell and end-caps) in contact with hydrogen gas are fabricated from the precipitation-strengthened austenitic stainless steel A286. This material is favorable for high-pressure hydrogen pressure vessels since it is resistant to hydrogen embrittlement under standard design stresses and can be heat treated to relatively high strength levels. Test specimens are located in the main chamber of the pressure vessel, and mechanical load is transferred from the test frame actuator to the specimen through a linkage (pull rod) that penetrates the bottom-cap pressure boundary. In addition to this primary chamber, the vessel features a secondary balance chamber to ensure an equal and opposing force is applied to the pull rod during pressurization 
so that the specimen sustains no net mechanical load. Since the pull rod is intended to transfer dynamic mechanical loads from the test-frame actuator to the test specimen, seals between the pull rod and bottom-cap bore must be suitable for dynamic motion. For this application, U-cup seals fabricated from graphite-reinforced Teflon ${ }^{\circledR}$ minimize gas leakage between the pull rod and bottom-cap bore while imposing manageable friction forces on the pull rod. Another desirable characteristic associated with the U-shaped cross-section is that the sealing force is a function of gas pressure. Recognizing that dynamic seals impose friction forces on the pull rod, the pressure vessel is equipped with an internal load cell to directly measure mechanical load sustained by the test specimen. This custom-designed load cell is essentially an aluminum structural component with Karma strain gauges. One challenge encountered with this strain gauge-based load cell is that the output signal drifts during initial exposure to hydrogen gas. However, the load cell output eventually stabilizes and the calibration factor is not affected. Other instrumentation connected to test specimens inside the pressure vessel include a linear variable differential transformer (LVDT) for measuring displacement, electrical leads for applying current and sensing voltage for a direct current potential difference (DCPD) crack measurement system, and thermocouples. Unlike the strain gauge-based load cell, the LVDT output signal does not exhibit time-dependent drift during initial exposure to hydrogen gas. Polymer feedthroughs located in the top-cap pressure boundary encapsulate electrical leads for the load cell, LVDT, DCPD system, and thermocouples.

The dynamic-load system is essential for performing certain types of material tests required for developing and implementing standards for hydrogen containment components, such as fatigue crack initiation and fatigue crack growth tests. Material tests performed with the dynamic-load system essentially follow ASTM standards with mechanical loading rates selected judiciously. This system in the Hydrogen Effects on Materials Laboratory has been primarily employed to measure fatigue crack initiation and fatigue crack growth properties for ferritic and martensitic steels, austenitic stainless steels, and aluminium alloys under hydrogen gas pressures up to $100 \mathrm{MPa}$ and load-cycle frequencies ranging from 0.001 to $10 \mathrm{~Hz}$. The dynamic-load system operates exclusively at ambient temperature, i.e., the system has no mechanism for varying temperature.

\subsection{Static-Load Crack Growth Testing in High-Pressure Hydrogen Gas}

This system was designed specifically for performing material tests to measure time-dependent subcritical crack extension under static mechanical loading in high-pressure hydrogen gas. While the dynamic-load system requires a pressure vessel coupled to a mechanical test frame, the static-load crack growth system consists only of pressure vessels rated for $200 \mathrm{MPa}$ pressure (Fig. 2a). The test specimens are not mechanically loaded by an external device; rather, typical specimens are self-loaded by tightening a bolt against a reaction pin (Fig. 2b). This loading mechanism subjects the test specimen to a constant-displacement condition. Under this loading condition, the measured properties include the crack velocity and the threshold stress-intensity factor $\left(\mathrm{K}_{\mathrm{TH}}\right)$ at crack arrest.

Although the functionality of the static-load crack growth system varies considerably compared to the dynamic-load system, the pressure vessel designs are similar. For example, the custom-designed pressure vessels for the static-load crack growth system consist of a shell with two end-caps. The pressure-boundary components in contact with hydrogen gas are fabricated from the high-strength stainless steel A286. The static-load crack growth system vessels require only the main end-cap seals, which are modified Bridgman metal-to-metal seals. The test specimens are seated in two cradles that attach to the end-caps. The pin reacting against the bolt threaded into the test specimen is instrumented with strain gauges, so that these pins serve as load cells. As a result, the mechanical load applied to the specimen can be measured continuously as a function of time. Similar to strain gauges in the dynamicload system, the output signals from strain gauges bonded to the reaction pins can drift during exposure to hydrogen gas. Electrical leads for the strain gauges are routed into feedthroughs located in the pressure vessel end-caps. The assembled pressure vessels are located in secondary-containment vessels for safety purposes, i.e., potential leaks from the seals or gas supply fittings can be captured in the containment vessel and vented outside the laboratory. 


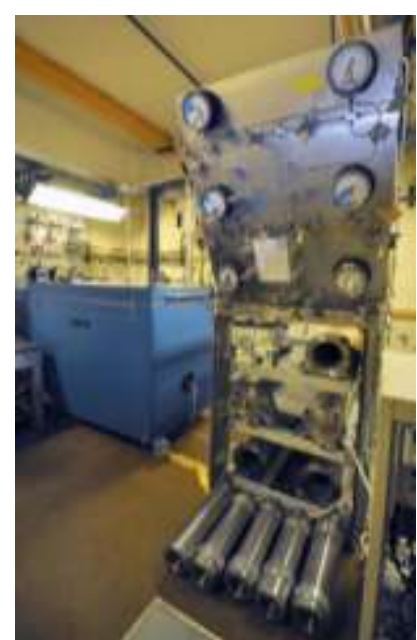

(a)

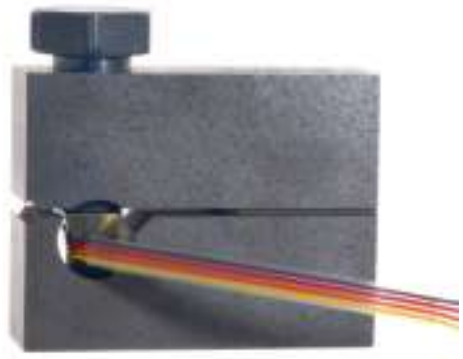

(b)

Figure 2. (a) Components in the static-load crack growth testing in high-pressure hydrogen gas system include the primary pressure vessels (bottom), secondary containment vessels, gas distribution manifold, and environmental chamber (left); (b) bolt-load compact test specimen for measuring subcritical crack extension under static mechanical loading

The test method applied in the static-load crack growth system follows the ASTM E1681 standard. One appealing aspect of this method is that multiple specimens can be tested concurrently in one pressure vessel. In the Hydrogen Effects on Materials Laboratory, typical bolt-load compact specimen dimensions (Fig. 2b) allow insertion of 8 specimens into each pressure vessel. In addition, the number of electrical leads can accommodate strain gauges on 8 load-reaction pins. This static-load crack growth system has been applied to measure time-dependent subcritical crack extension for ferritic and martensitic steels, austenitic stainless steels, and aluminium alloys in hydrogen gas at pressures as high as $200 \mathrm{MPa}$. These subcritical cracking tests can also be performed as a function of temperature. One of the 6 pressure vessel assemblies in the system can be located in an environmental chamber having a temperature range from 203 to $443 \mathrm{~K}$. In the higher temperature range, the pressure vessel rating must be reduced, i.e., maximum operating pressures are less than $200 \mathrm{MPa}$.

\subsection{Thermal Precharging in High-Pressure Hydrogen Gas}

The functionality of this system is considerably different compared to the two systems previously described. In particular, while material specimens in the dynamic-load testing and static-load crack growth testing systems are concurrently subjected to mechanical loading and hydrogen gas exposure, specimens in the thermal precharging system are exposed to hydrogen gas and then material testing is performed subsequently. From a material testing perspective, the environmental boundary conditions are distinct, i.e., in one case the hydrogen source is external to the specimen and in the other case the hydrogen source is internal to the specimen during mechanical loading. When material testing is performed subsequent to hydrogen gas exposure, the test methods are not constrained by the physical boundaries of hydrogen containment vessels. Consequently, any conventional mechanical test method can be applied to hydrogen-exposed material specimens to measure properties such as tensile strength and ductility, fatigue strength, fatigue crack growth rates, and time-dependent subcritical cracking thresholds.

The thermal precharging in high-pressure hydrogen gas system is comprised of two central components: pressure vessels (Fig. 3a) and furnaces (Fig. 3b). The pressure vessels are nearly identical in design to vessels in the static-load crack growth testing system, except that vessels in the thermal precharging system have only one end-cap. This single end-cap also features the modified Bridgman metal-to-metal seal. Two types of commercially available pressure vessels are employed in the thermal precharging system (Fig. 3a), which are distinguished by their internal volumes. These internal volumes are $50 \mathrm{~mm}$ diameter x $250 \mathrm{~mm}$ length and $75 \mathrm{~mm}$ diameter x $150 \mathrm{~mm}$ length, respectively. 
The two types of pressure vessels allow a broader range of dimensions for the material test specimens inserted into the vessels. The assembled pressure vessels are placed in secondary containment vessels located inside the furnaces. Each secondary containment vessel can accommodate one $75 \mathrm{~mm}$ diameter primary vessel or two $50 \mathrm{~mm}$-diameter primary vessels. Since the thermal precharging system consists of two furnaces (Fig. 3b), multiple hydrogen exposures can be performed in parallel with varying material test specimen dimensions, hydrogen gas pressures, and temperatures. For each type of pressure vessel, the maximum operating pressure is $138 \mathrm{MPa}$ at the maximum furnace temperature of $573 \mathrm{~K}$.

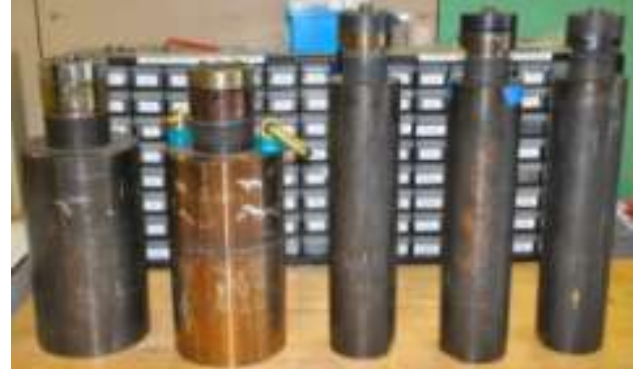

(a)

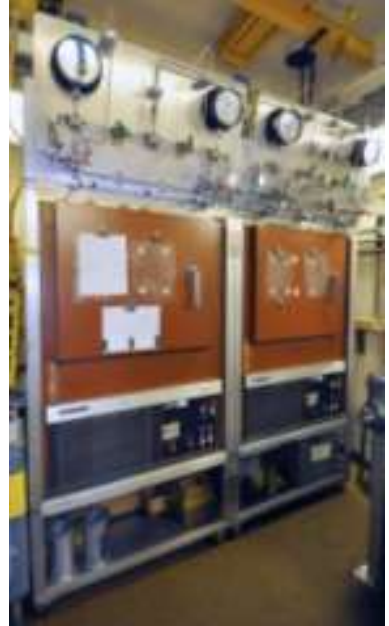

(b)

Figure 3. Thermal precharging in high-pressure hydrogen gas system consisting of (a) primary pressure vessels, and (b) furnaces

The thermal precharging method is a relatively simple concept, in which material test specimens are exposed to high-pressure hydrogen gas at elevated temperature. In principle, the pressure and temperature are selected based on the material and specimen dimensions to develop a targeted uniform hydrogen concentration in the specimen. In practice, this method is most reliable for materials with high activation energy for hydrogen diffusion. In these materials, the hydrogen diffusivity can be relatively low at ambient temperature, but it increases dramatically as a function of increasing temperature. As a result, uniform hydrogen concentrations can be developed in conventional-sized material test specimens in reasonable timeframes during elevated-temperature exposure to highpressure hydrogen gas. In addition, this hydrogen-precharged specimen can be maintained at ambient temperature without significant hydrogen egress for prolonged times, which enhances the reliability of material testing since the hydrogen concentration can be defined. For the thermal precharging system in the Hydrogen Effects on Materials Laboratory, material test specimens are most vulnerable to hydrogen egress during cooling of the pressure vessels following termination of elevated-temperature charging. During this cooling from the charging temperature, the pressure vessels require approximately 12 to $16 \mathrm{~h}$ to reach ambient temperature. Although hydrogen gas remains in the pressure vessels during cooling, the gas pressure and temperature conditions deviate from those prescribed during hydrogen charging, creating a thermodynamic driving force for hydrogen egress from the test specimens. For materials with high activation energy for hydrogen diffusion and conventional-sized specimens (e.g., millimeter dimensions), this hydrogen egress is typically confined to the near-surface volume. Examples of materials that are suitable for thermal precharging and subsequent material testing at ambient (or lower) temperature include the austenitic stainless steels and nickel alloys. 


\subsection{EXAMPLES OF TESTING IN HYDROGEN EFFECTS ON MATERIALS LABORATORY}

\subsection{Fatigue Crack Growth Testing in High-Pressure Hydrogen Gas}

The objective of this material testing was to enable the safe design of hydrogen pressure vessels by measuring the fatigue crack growth rates of ASME code-qualified steels in high-pressure hydrogen gas [1]. One class of steels currently used for hydrogen gas vessels is the ASME SA-372 series. These steels are candidates for higher-pressure hydrogen containment vessels with service pressures up to $100 \mathrm{MPa}$. While Article KD-10 in Section VIII, Division 3 of the ASME Boiler and Pressure Vessel Code ("Special Requirements for Vessels in High Pressure Gaseous Hydrogen Transport and Storage Service") provides a design-life framework for these high-pressure vessels, a material property database does not exist to enable the analysis. This study addresses such voids in the database by measuring the fatigue crack growth rate $(\mathrm{da} / \mathrm{dN})$ vs. stress-intensity factor range $(\Delta \mathrm{K})$ relationship for ASME SA-372 Grade J steel in $100 \mathrm{MPa}$ hydrogen gas.

Three different heats of steel were tested in this study, where the alloy composition, heat treatment, and mechanical properties of the steels conformed to Grade $\mathrm{J}$ in the ASME SA-372 standard ("Specification for Carbon and Alloy Steel Forgings for Thin-Walled Pressure Vessels"). Fatigue crack growth rate testing on the SA-372 Grade J steels was conducted following guidance in ASTM Standard E647-05 [2]. The test specimens, designed as the compact tension (CT) geometry, were extracted from seamless pipe test rings. After inducing precracks in the CT specimens by cyclic mechanical loading in air, fatigue crack growth tests were performed on the SA-372 Grade J compact tension specimens in $100 \mathrm{MPa}$ hydrogen gas using the dynamic-load testing system described in section 2.1. Mechanical loading was applied to the CT specimens at constant amplitude (i.e., fixed minimum and maximum loads), in which the ratio of minimum load to maximum load, $\mathrm{R}$, was equal to 0.2 or 0.5 and the load-cycle frequency was $0.1 \mathrm{~Hz}$. The loading and unloading rates were programmed to be constant in each cycle (i.e., triangular loading wave form) using the internal load cell as the feedback transducer in the control loop.

The fatigue crack growth rate, da/dN, vs. stress-intensity factor range, $\Delta \mathrm{K}$, relationships measured for the SA-372 Grade J steels in $100 \mathrm{MPa}$ hydrogen gas are displayed in Fig. 4. Notably, each steel data set in hydrogen gas shows fatigue crack growth rates that are at least one order of magnitude higher than crack growth rates in air. (The da/dN vs. $\Delta \mathrm{K}$ relationship for HSLA steels in air is from ASME Article KD-4.) Such elevated fatigue crack growth rates are a manifestation of hydrogen embrittlement. While comparison of da/dN vs. $\Delta \mathrm{K}$ data can demonstrate the relative sensitivity of materials to hydrogen embrittlement, such comparisons do not enable quantitative design-life evaluations of hydrogen containment structures. Rather, the da/dN vs. $\Delta \mathrm{K}$ relationship must be used in conjunction with structural analysis to establish design life. This fatigue crack growth-based designlife evaluation is specified in ASME Article KD-10 for hydrogen pressure vessels. The intent of the design-life analysis is to calculate the incremental extension of a postulated flaw in the pressure vessel as a function of the number of pressure cycles. This fatigue crack growth-based design-life analysis is an effective approach for assuring the safety of hydrogen containment structures that are susceptible to hydrogen embrittlement and subjected to pressure cycling.

\subsection{Time-Dependent Subcritical Crack Extension Testing in High-Pressure Hydrogen Gas}

The objective of this study was to measure the threshold stress-intensity factor $\left(\mathrm{K}_{\mathrm{TH}}\right)$ for subcritical crack extension under both rising-displacement and constant-displacement loading conditions for lowto-intermediate strength pressure vessel steels in high-pressure hydrogen gas [3]. Reliable and appropriately conservative subcritical cracking thresholds measured under quasi-static loading in highpressure hydrogen gas are necessary inputs to effective fracture mechanics-based life prediction assessments. This material testing was conducted in $103 \mathrm{MPa}$ hydrogen gas, since this pressure is generally viewed as the upper limit for compressed hydrogen storage and delivery in a hydrogen fuel infrastructure. Several pressure vessel steels were tested with emphasis on lower-strength steels that are technologically relevant to hydrogen storage and delivery components. Steels with ultimate tensile 
strengths less than $950 \mathrm{MPa}$ are of particular interest since higher-strength steels are generally considered incompatible with high-pressure hydrogen gas.

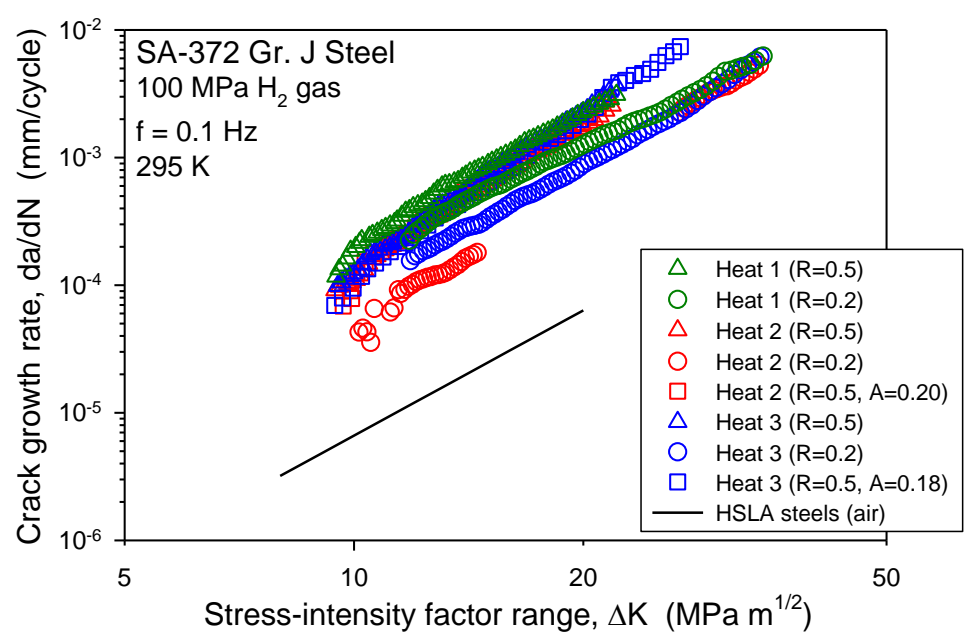

Figure 4. Fatigue crack growth rate relationships for three SA-372 Gade J steel heats in $100 \mathrm{MPa}$ hydrogen gas

Eleven heats of commercially produced Cr-Mo and Ni-Cr-Mo low-alloy pressure vessel steels were examined in this study. These pressure vessel steels were acquired as curved panels cut from seamless pipe test-rings, which were heat treated concurrently with commercial pressure vessels and thus have representative microstructures. For the constant-displacement tests, bolt-load compact test specimens (e.g., Fig. 2b) were extracted from the steel panels and designed according to ASTM standard E168103 [4]. After inducing precracks in the compact test specimens by cyclic mechanical loading in air, the specimens were placed into a glovebox filled with approximately $0.1 \mathrm{MPa}$ purified argon containing oxygen and moisture levels controlled to below 2 vppm $\mathrm{O}_{2}$ and $8 \mathrm{vppm} \mathrm{H}_{2} \mathrm{O}$ to minimize further formation of surface oxide on the precrack tip. The crack opening displacement was applied to the precracked specimens inside the glovebox using either A286 stainless steel bolts or $\mathrm{Cu}$-Be bolts reacting against $\mathrm{Cu}$-Be pins. Pressure vessels from the static-load crack growth testing system (section 2.2) were also positioned in the glovebox, so that the bolt-loaded specimens were sealed in these pressure vessels while still located inside the glovebox. The sealed pressure vessel was then removed from the glovebox, placed inside a secondary containment vessel, connected to the gas distribution manifold, and filled with $103 \mathrm{MPa}$ hydrogen gas. For the rising-displacement tests, compact tension (CT) specimens were similarly extracted from the steel panels and designed according to ASTM Standard E1737-96 [5]. Following precracking in air, these specimens were inserted into the pressure vessel of the dynamic-load testing system (section 2.1). The pressure vessel was filled with $103 \mathrm{MPa}$ hydrogen gas, then the test specimens were subjected to mechanical loading under a constant displacement rate of $0.051 \mathrm{~mm} / \mathrm{min}$ imposed by the test frame actuator.

The subcritical cracking thresholds measured from both test methods are plotted as a function of steel yield strength in Fig. 5. In the constant-displacement method, the crack extends in a time-dependent manner under decreasing mechanical load, which ultimately leads to crack arrest. At this point, the threshold stress-intensity factor can be calculated, and this quantity is termed the arrest threshold $\left(\mathrm{K}_{\mathrm{TH}}\right)$. In contrast, the critical event during the rising-displacement method is the onset of subcritical cracking from the stationary precrack, and for this reason the test measures the initiation threshold $\left(\mathrm{K}_{\mathrm{THi}}\right)$. Although thresholds from each test method decrease as a function of increasing yield strength, the absolute values vary for the two methods. In particular, $\mathrm{K}_{\mathrm{THa}}$ exceeds $\mathrm{K}_{\mathrm{THi}}$, although this difference narrows considerably at higher yield strength. This study indicates that subcritical cracking thresholds measured under constant-displacement loading are fundamentally different properties than thresholds measured under rising-displacement loading. Since these thresholds are essential material properties in damage-tolerant life prediction analyses of structures, it is essential that lower-bound values are 
employed in such analyses. Reliable and conservative subcritical cracking test methods for lowerstrength pressure vessel steels likely require active-loading measurements of initiation thresholds.

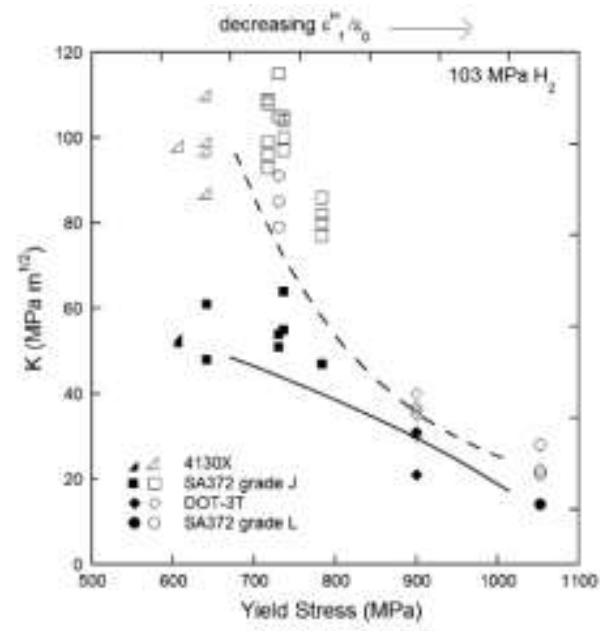

Figure 5. Crack-arrest thresholds ( $\mathrm{K}_{\mathrm{TH}}$ ) from constant-displacement tests (open symbols) and crackinitiation thresholds $\left(\mathrm{K}_{\mathrm{THi}}\right)$ from rising-displacement tests (filled symbols) plotted as a function of yield strength. The measurements are for the pressure vessels steels 4130X, SA-372 Grade J, DOT-3T, and SA-372 Grade L in $103 \mathrm{MPa}$ hydrogen gas.

\subsection{Tensile Testing of Hydrogen-Precharged Specimens}

In this study, thermal precharging in hydrogen gas was applied to measure the effects of internal hydrogen on the tensile fracture properties of seven type 316 stainless steel alloys [6]. Type 316 stainless steel is a common choice for structural materials in modest-volume, high-pressure gas components such as manifold tubing, valves, and fittings. The environmental compatibility and fracture resistance of type 316 stainless steel make it attractive for high-pressure applications, including hydrogen gas service. Although the technical literature on hydrogen-assisted fracture of type 316 stainless steels is reasonably comprehensive, the effects of certain intersections of material, environmental, and mechanical variables remain undefined. Tensile fracture properties were measured with the aim of assessing variations in hydrogen-assisted fracture due to alloy composition and microstructure (annealed vs. strain-hardened).

Seven type 316 stainless steels were featured in this study, which varied according to processing method (i.e., argon oxygen decarburization, vacuum induction melting, vacuum arc remelting) and alloy composition. Round tensile specimens with $4 \mathrm{~mm}$ gauge diameter (ASTM E8 subsized geometry) were machined from annealed and strain-hardened bars of the stainless steels. Tensile specimens were exposed to $138 \mathrm{MPa}$ hydrogen gas at $573 \mathrm{~K}$ for about 10 days in the thermal precharging system (section 2.3). The exposure time was sufficient to allow a uniform hydrogen concentration (approximately $135 \mathrm{wppm}$ ) to develop across the full diameter of the specimens. Following precharging, the tensile specimens were strained on a conventional mechanical test frame at ambient conditions under a constant displacement rate of $0.02 \mathrm{~mm} \mathrm{~s}^{-1}$, corresponding to a strain rate of $\sim 1.5 \times 10^{-3} \mathrm{~s}^{-1}$ in the plastic regime prior to necking.

Hydrogen degrades the tensile ductility of both annealed and strain-hardened 316 alloys, but the effect is mild for most alloys as reduction of area (RA) values are in the range 58 to $72 \%$ with the exception of strain-hardened alloy F, which has an RA of 47\%. For hydrogen-precharged materials, RA is only slightly lower for the strain-hardened microstructures compared to the annealed microstructures. In contrast, a clear correlation between RA and nickel content is apparent; RA is greater for alloys with greater nickel content (Figures $6 \mathrm{a}$ and $6 \mathrm{~b}$ ). The beneficial role of nickel appears to nearly saturate for $\mathrm{Ni}>12 \mathrm{wt} \%$, at least in the context of using RA to assess hydrogen-assisted fracture. Identifying the 
effect of nickel content on hydrogen-assisted fracture is essential to guide selection of stainless steels for hydrogen gas components.

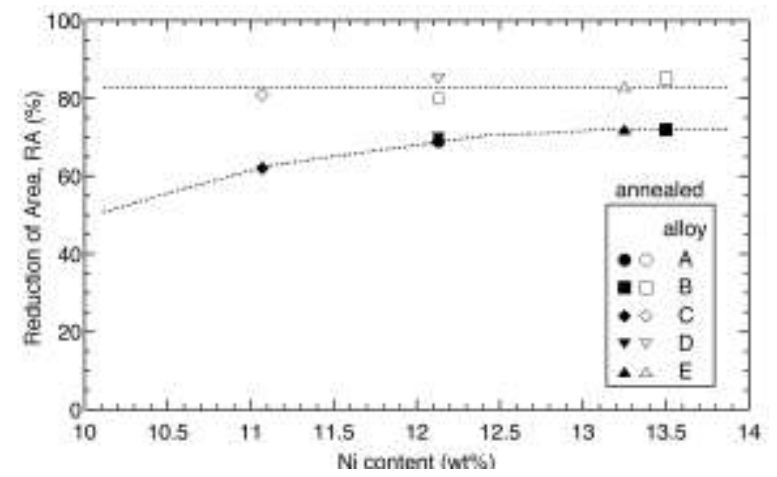

(a)

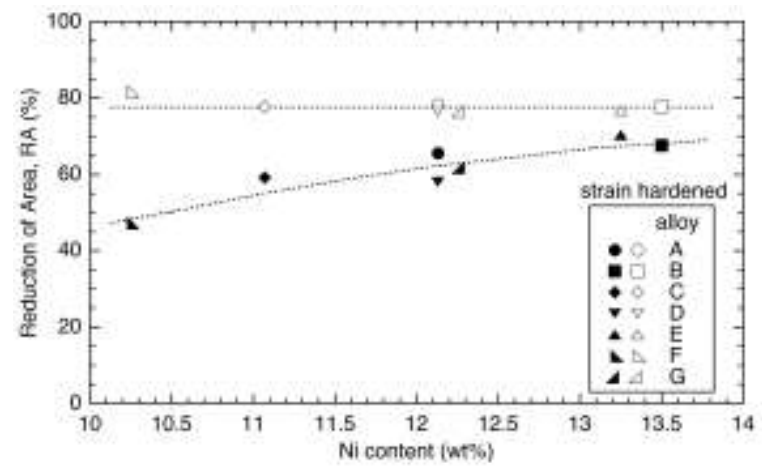

(b)

Figure 6. Tensile ductility as a function of nickel content for both (a) annealed and (b) strain-hardened stainless steels. Open symbols denote the non-charged materials; filled symbols represent hydrogenprecharged materials.

\subsection{SUMMARY}

- The Hydrogen Effects on Materials Laboratory at Sandia National Laboratories features three distinct test systems: dynamic-load testing in high-pressure hydrogen gas, static-load crack growth testing in high-pressure hydrogen gas, and thermal precharging in high-pressure hydrogen gas. Collectively, the systems enable measurement of mechanical properties such as tensile ductility, time-dependent subcritical crack extension, and accelerated fatigue crack initiation and growth over a range of hydrogen exposure and mechanical stress conditions. The common specification for the systems is to expose materials to hydrogen gas at high pressure, in which the maximum pressure for each system is at least $138 \mathrm{MPa}$.

- Three examples of testing in the Hydrogen Effects on Materials Laboratory were summarized: fatigue crack growth testing of pressure vessel steels in $100 \mathrm{MPa}$ hydrogen gas, time-dependent subcritical crack extension testing of pressure vessel steels in 103 MPa hydrogen gas, and tensile testing of hydrogen-precharged stainless steels. These data are essential for materials selection and design-life analyses of hydrogen containment components to ensure their safety.

\subsection{ACKNOWLEDGMENTS}

Support was provided by the U.S. Department of Energy Fuel Cell Technologies Office through the Hydrogen Safety, Codes and Standards sub-program element. Sandia National Laboratories is a multiprogram laboratory managed and operated by Sandia Corp., a wholly owned subsidiary of Lockheed Martin Corp., for the U.S. Department of Energy's National Nuclear Security Administration under Contract DE-AC04-94AL85000.

\subsection{REFERENCES}

1. Somerday, B., San Marchi, C., and Nibur, K., Measurement of Fatigue Crack Growth Rates for SA-372 Gr. J Steel in 100 MPa Hydrogen Gas Following Article KD-10, 2013 ASME Pressure Vessels and Piping Division Conference, ASME, New York, PVP2013-97455, 2013.

2. Standard Test Method for Measurement of Fatigue Crack Growth Rates, Annual Book of ASTM Standards, ASTM E647-05, ASTM International, West Conshohocken, PA, 2005.

3. Nibur, K.A., Somerday, B.P., San Marchi, C., Foulk, J.W., Dadfarnia, M., and Sofronis, P., The Relationship Between Crack-Tip Strain and Subcritical Cracking Thresholds for Steels in HighPressure Hydrogen Gas, Metallurgical and Materials Transactions A, 44A, 2013, pp. 248-269. 
4. Standard Test Method for Determining Threshold Stress Intensity Factor for EnvironmentAssisted Cracking of Metallic Materials, Annual Book of ASTM Standards, ASTM E1681-03, ASTM International, West Conshohocken, PA, 2003.

5. Standard Test Method for J-integral Characterization of Fracture Toughness, Annual Book of ASTM Standards, ASTM E1737-96, ASTM International, West Conshohocken, PA, 1996.

6. San Marchi, C., Somerday, B.P., Tang, X. and Schiroky, G.H., Effects of Alloy Composition and Strain Hardening on Tensile Fracture of Hydrogen-Precharged Type 316 Stainless Steels, International Journal of Hydrogen Energy, 33, 2008, pp. 889-904. 